\title{
An Exploratory Phase II Study of Eribulin Re-challenge After Short Term Therapy of 5-Fluorouracil for HER2 Negative, Advanced or Recurrent Breast Cancer
}

\author{
TSUTOMU TAKASHIMA ${ }^{1}$, SHIGEHIKO NISHIMURA ${ }^{2}$, HIDEMI KAWAJIRI ${ }^{3}$, YOKO MIZUYAMA ${ }^{4}$, \\ TAKEO NISHIMORI ${ }^{5}$, SHIGEHITO YAMAGATA ${ }^{6}$, SHINYA TOKUNAGA ${ }^{7}$, KENJI TEZUKA $^{8}$, \\ SEIKA TEI ${ }^{9}$, TAKESHI SUNAMI ${ }^{10}$, KATSUMI IKEDA ${ }^{11}$, YOSHINARI OGAWA ${ }^{11}$, SHINICHIRO KASHIWAGI $^{1}$, \\ SATORU NODA ${ }^{1}$, NAOYOSHI ONODA ${ }^{12}$, TETSURO ISHIKAWA ${ }^{13}$, SHINZOH KUDOH ${ }^{14}$, \\ MINORU TAKADA ${ }^{15}$, KOSEI HIRAKAWA ${ }^{13}$ and MASAICHI OHIRA ${ }^{1}$ \\ ${ }^{1}$ Department of Breast and Endocrine Surgery, \\ Osaka City University Graduate School of Medicine, Osaka, Japan; \\ ${ }^{2}$ Department of Surgery, Sumitomo Hospital, Osaka, Japan; \\ ${ }^{3}$ Department of Breast Surgery, Ishikiri Seiki Hospital, Higashi-Osaka, Japan; \\ ${ }^{4}$ Department of Surgery, Kashiba Seiki Hospital, Kashiba, Japan; \\ ${ }^{5}$ Department of Surgery, Ikuwakai Memorial Hospital, Osaka, Japan; \\ ${ }^{6}$ Department of Surgery, Seichokai Fuchu Hospital, Izumi, Japan; \\ ${ }^{7}$ Department of Clinical Oncology, Osaka City General Hospital, Osaka, Japan; \\ ${ }^{8}$ Department of Breast Surgery, Izumi City General Hospital, Izumi, Japan; \\ ${ }^{9}$ Department of Breast Surgery, Iseikai Hospital, Osaka, Japan; \\ ${ }^{10}$ Department of Surgery, PL Hospital, Tondabayashi, Japan; \\ ${ }^{11}$ Department of Clinical Oncology, Osaka City General Hospital, Osaka, Japan; \\ ${ }^{12}$ Department of Surgery, Kuma Hospital, Kobe, Japan; \\ ${ }^{13}$ Department of Surgery, Kashiwara Municipal Hospital, Osaka, Japan; \\ ${ }^{14}$ Department of Internal Medicine, Osaka Socio-Medical Center Hospital, Osaka, Japan; \\ ${ }^{15}$ Department of Internal Medicine, Hanwa Daini Senboku Hospital, Sakai, Japan
}

\begin{abstract}
Background/Aim: In our previous study, first-line eribulin (ERI) showed 25 weeks of progression-free survival (PFS). This study investigated the efficacy and safety of ERI readministration in metastatic breast cancer $(M B C)$ patients. Patients and Methods: HER2-negative MBC patients who had never received chemotherapy for $M B C$ received first-line ERI for 18 weeks if they did not have disease progression, and then one cycle of S-1 before ERI re-administration. Results: Twelve patients received ERI re-administration. The PFS of re-
\end{abstract}

This article is freely accessible online.

Correspondence to: Tsutomu Takashima (ORCID ID: 0000-00020417-6674), Department of Breast and Endocrine Surgery, Osaka City University Graduate School of Medicine, 1-4-3 Asahimachi Abeno, Osaka 5458585, Japan. Tel: +81 666453838, Fax: +81 666466450, e-mail: tsutomu-@rd5.so-net.ne.jp

Key Words: Metastatic breast cancer, eribulin, re-administration, S-1. administered ERI was 13 weeks. Total duration of ERI use was 30 weeks. The incidence and severity of adverse events were consistent with previous reports. Conclusion: In the first-line setting, the total PFS of eribulin was extended by $S-1$ administration before disease progression, compared with that of our previous report.

In a phase III randomized trial, eribulin (ERI) showed a significant improvement in overall survival (OS) compared to treatment of the physician's choice in patients with heavily pretreated metastatic breast cancer (MBC) (1). In another phase III trial, the OS of ERI was almost the same as that of capecitabine in MBC patients who had previously received anthracycline and taxane treatment (2). Furthermore, the pooled analysis of these two trials revealed that ERI improved OS compared with controls significantly (3). In addition to prolongation of OS, non-hematological toxicities of ERI were generally mild and tolerable. It is thus suggested, that ERI would be appropriate for upfront regimen against MBC because it can maximize survival benefit with minimal toxicity. 


\section{TFS}

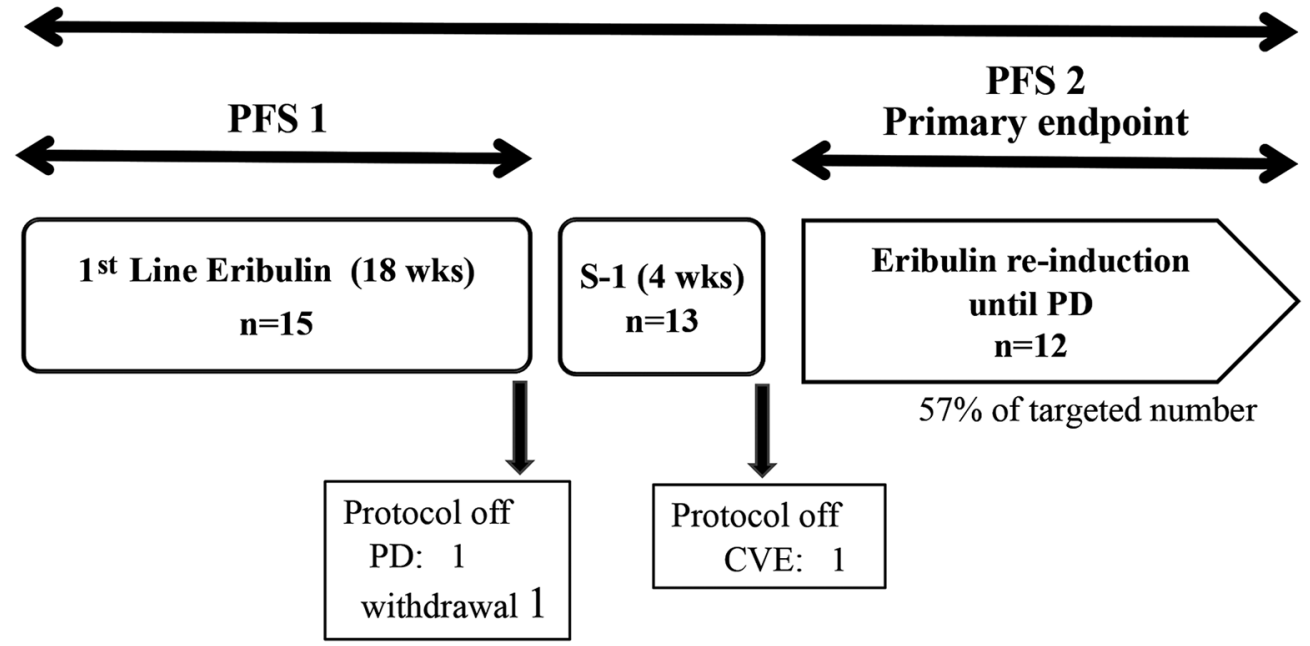

Figure 1. Study design and CONSORT diagram. TFS: Time to failure of strategy; PFS: progression-free survival; CVE: cerebrovascular event.

We previously conducted a phase II study to estimate the usefulness of ERI as a first-line chemotherapy for human epidermal growth factor receptor 2 (HER2)-negative MBC (4). Results demonstrated an objective response rate (ORR) of $54.3 \%$ and a progression-free survival (PFS) of 25 weeks with mild toxic profiles. The median time to partial response (PR) for the responding cases was seven weeks, the longest being 16 weeks. This result suggested that resistance to ERI might occur at around 4 months in the first-line setting. If at the time resistance occurs you change to a drug with a different mode of action, the resistant cells might retrieve sensitivity for ERI, which may thus extend the total duration of ERI. Actually, Toulmonde et al. have reported on the efficacy of docetaxel re-challenging for MBC patients (5).

This study was conducted to investigate the efficacy of rechallenge ERI in MBC patients who previously responded to ERI and to evaluate whether it contributes to prolonging the disease control period.

\section{Patients and Methods}

Patients. Key inclusion criteria included: female patients with histologically confirmed HER2-negative MBC; aged $\geq 20$ years; Eastern Cooperative Oncology Group performance status (ECOG PS) of 0 through 2; having measurable lesion(s) based on the Response Evaluation Criteria in Solid Tumors (RECIST) ver. 1.1 (6); without history of cytotoxic chemotherapy for MBC; elapsing at least 6 months since the completion of perioperative chemotherapy and adequate major organ functions including bone marrow. The patients who had previously received endocrine therapy, immunotherapy, or radiotherapy against $\mathrm{MBC}$ were allowed to participate in this study.

Key exclusion criteria included: active systemic infection; symptomatic brain tumor; pregnancy (including possible pregnancy); hypersensitivity to protocol drugs and their solvents; active concomitant malignancy; life-threatening liver metastasis or pulmonary lymphangiosis carcinomatosa; uncontrollable pleural effusion, ascites or pericardiac effusion. Patients who were deemed ineligible by the investigators were also excluded.

Study design. This phase II open-label, single-arm, multicenter trial was conducted at eight medical institutions in Japan. The study protocol and all amendments were approved by the institutional review board or local ethics committees of each participating facility. This study was executed according to the Declaration of Helsinki, the Japanese Guidelines for Clinical Research of the Ministry of Health, Labor and Welfare, and other relevant regulations. All participants provided written consents before their participation. This study was registered in the University Hospital Medical Information Network (UMIN) Center (ID: UMIN000019377).

Eligible patients started to receive ERI as the first-line chemotherapy and continued for 18 weeks (induction phase). Then, if they were not progressing, the regimen was switched to 80 $\mathrm{mg} / \mathrm{m}^{2} /$ day of S-1 for 4 weeks (S-1 phase). After that, ERI was rechallenged (Re-administration phase) (Figure 1).

ERI was administered at a dose of $1.4 \mathrm{mg} / \mathrm{m}^{2}$ over $2-5$ minutes weekly for two consecutive weeks, followed by a week's rest. For patients who could not be administrated ERI on day 8 (i.e., neutrophil count $<1,000 / \mathrm{mm}^{3}$, platelet count $<75,000 / \mathrm{mm}^{3}$, sgrade 2 non-hematological adverse events), they skipped day 8 administration, and the next cycle started on day 22 (Day 1 of the next cycle). The dose was reduced to $1.1 \mathrm{mg} / \mathrm{m}^{2}$ if at least one of the following criteria was met during the last cycle: neutrophil count $<500 / \mathrm{mm}^{3}$ for more than 7 days; presence of febrile neutropenia; grade 4 thrombocytopenia; and grade 3 or higher non-hematological toxicity. If, however, the toxicity did not improve, a further dose reduction to $0.7 \mathrm{mg} / \mathrm{m}^{2}$ was made. After the patients became refractory to ERI, they continued any treatment based on the discretion of investigators. Concomitant use of another anticancer therapy (e.g., endocrine therapy, molecular targeted therapy, 
immune therapy, and cytotoxic chemotherapy other than ERI) and any local treatment was prohibited. A bone modifying agent against bone metastases was allowed, if it had been used prior to the registration. Granulocyte colony-stimulating factor was permitted for already developed neutropenia, in line with the clinical practice guidelines (7), but not for prophylaxis.

The patients who have moved to the S-1 phase were administrated S-1 orally twice daily for 28 consecutive days, followed by 14 days off. Standard dosage of S-1 was determined by the body surface area (BSA) $\left(\mathrm{BSA}<1.25 \mathrm{~m}^{2} ; 80 \mathrm{mg} /\right.$ day, 1.25 $\mathrm{m}^{2} \leq \mathrm{BSA}<1.5 \mathrm{~m}^{2} ; 100 \mathrm{mg} /$ day, BSA $\leq 1.5 \mathrm{~m}^{2} ; 120 \mathrm{mg} /$ day).

The primary endpoint was progression-free survival (PFS) of readministrated ERI (PFS2). The secondary endpoints included disease control rate (DCR) of re- administrated ERI, time to failure of strategy (TFS), OS and safety.

Assessment. Baseline information of patients was collected within 28 days prior to the initial ERI administration. Radiographic assessments for baseline tumor with computerized tomography scan or magnetic resonance imaging scan were also carried out within 28 days before the start of protocol treatment. Assessments of the targeted lesions continued every six weeks thereafter, by the same imaging modality. Tumor assessments were classified into complete response (CR), PR, stable disease (SD) and progressive disease (PD) based on the RECIST ver. 1.1 (6). PFS1 was defined as the period from the first administration of ERI to confirmed disease progression or death from any cause. PFS2 was defined as the period from start of ERI re-administration after S-1 phase to disease progression or death from any cause. OS was defined as the time from the initial dose of ERI to death from any cause. TFS was defined as the time from the first administration of ERI to the end of the protocol treatment for any reason. Adverse events, vital signs, physical status, and results of laboratory tests were assessed at the patients visits during the study. All observed adverse events were described in accordance with the Common Terminology Criteria for Adverse Events ver. 4.0 (8).

Statistical analysis. The following assumptions were made to calculate target enrollment. In our previous phase II trial estimating first-line ERI treatment (4), the median PFS was 25 weeks, however, the median PFS for patients who could continue ERI for more than 18 weeks was 31 weeks. Eighteen weeks after the first dose of eribulin, the patients received four weeks of S-1 and then, rechallenge eribulin. The treatment period should be at least 2.5 months for the patients' benefit, considering the two weeks of interval between S-1 and the reintroduced ERI. On the other hand, the median PFS was 4.1 months (95\%CI=3.5-4.3 months) in Study 301, a phase III study evaluating early use of eribulin (median 2nd line) (2).

Based on these results, the threshold PFS for this eribulin readministration therapy was set to 2.5 months and the expected PFS was set to 4.0 months. Given a one-sided $\alpha$ error of 0.1 , and power $80 \%$, registration period is 2.5 years, 6 months until the readministration phase, and 6 months follow-up after readministration, the minimum required number of cases for eribulin re-administration should be 21 patients. In our first-line trial described above, $30 \%$ of patients had progressive disease by 18 weeks, therefore, the number of registrations to obtain at least 21 patients for re-administration therapy was estimated to be 30 patients. Approximately $10 \%$ of participants were expected to be ineligible, thus, we aimed to enroll 33 patients.
Table I. Patient characteristics.

\begin{tabular}{llc}
\hline & & Number \\
\hline $\mathrm{n}$ & & 15 \\
Age & Median(range) & 64 y.o. $(42-76)$ \\
PS & 0 & 13 \\
& 1 & 2 \\
Setting & Recurrence & 8 \\
& Inoperable & 7 \\
ER & Positive & 11 \\
& Negative & 4 \\
DFI (n=8) & Median (range) & 72 mo. $(25-142)$ \\
Metastatic site & Lung & 10 \\
& Liver & 9 \\
& (Lung+Liver) & 5 \\
& Bone & 8 \\
& Lymph node & 2 \\
& Skin & 1 \\
& Brain & 1 \\
\hline
\end{tabular}

PS: Performance status; ER: estrogen receptor; DFI: disease-free interval.

The primary outcome was assessed in the full analysis set. The median values with $95 \%$ confidence interval (CI) for the PFS of eribulin re-administration therapy were estimated with the KaplanMeier method.

\section{Results}

Patients. A total of 15 patients with HER2-negative MBC were enrolled between November 2015 and February 2018. The baseline patients' characteristics are summarized in Table I. The median age was 64 years (range $=42-76$ years), and all patients had ECOG PS 0 or 1 . Eight patients $(53 \%)$ had recurrent disease after surgery with a median diseasefree interval of 72 months (range=25-142 months), and seven patients (47\%) had distant metastasis at the presentation. Eleven patients $(73 \%)$ had hormonal receptor-positive disease.

Of the 15 enrolled patients, two patients dropped out of protocol treatment; one patient had disease progression and the other according to his preference during the first-line administration of ERI. One patient had a cerebrovascular event during the S-1 phase and discontinued the protocol. Finally, 12 patients $(80 \%)$ received re-administration of ERI. Eventually, $57 \%$ of the eribulin re-administration cases specified in the protocol were recruited (Figure 1).

Median follow up period was 82 weeks (range $=46-146$ weeks) for all patients (data cut-off; August 15, 2019).

Efficacy analysis. The ORR in the induction phase of ERI was $60 \%$ (PR; 9, SD; 5, PD; 1). In the S-1 phase, all 13 patients held efficacy of ERI (PR;2 $\square \mathrm{SD} ; 11)$ and two patients with PR had also PR in the ERI induction phase. 

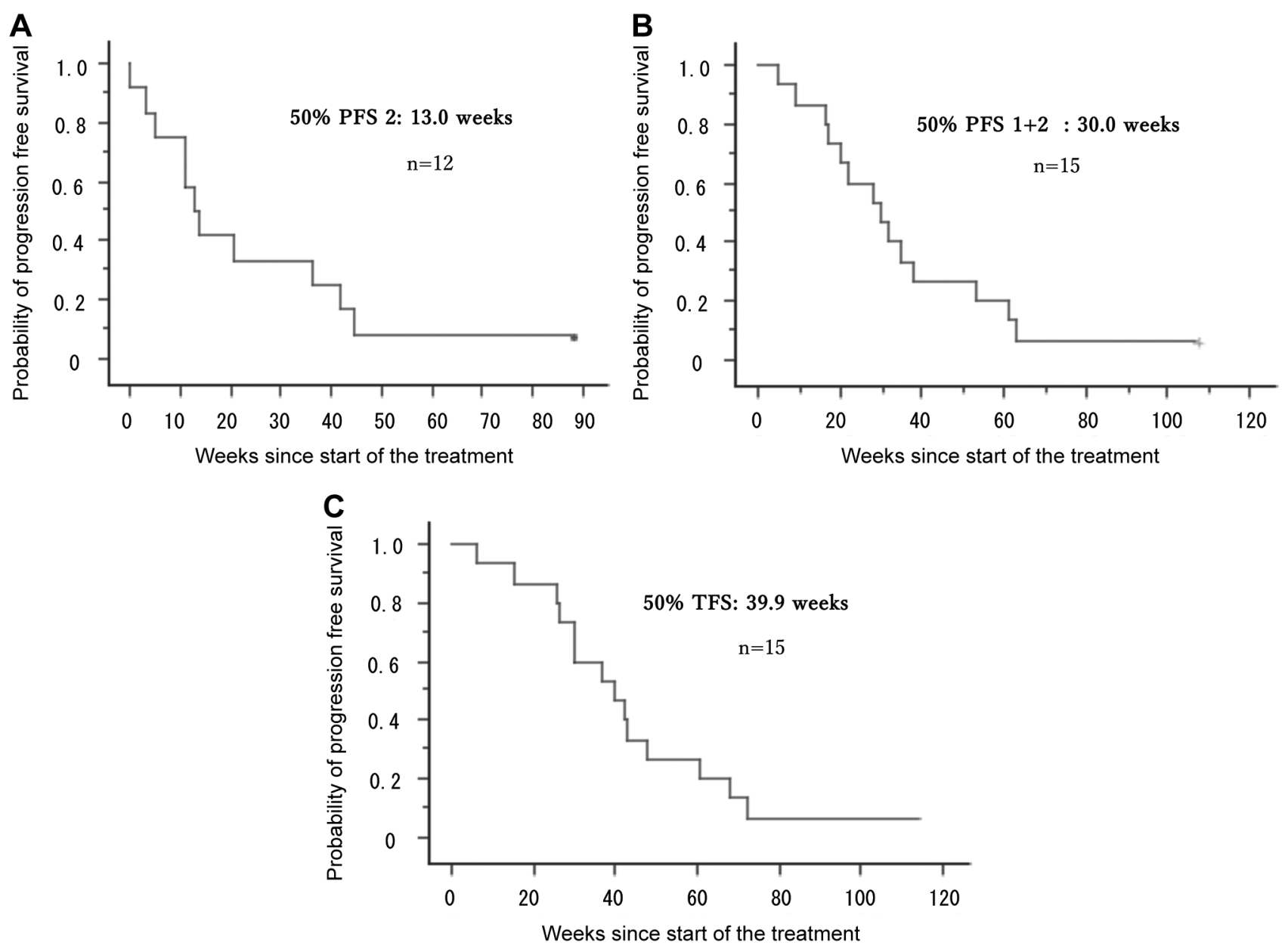

Figure 2. Efficacy of eribulin re-administration on the progression free survival and the duration of treatment. A) Progression-free survival (PFS) of eribulin re-challenge (PFS 2). B) Total duration of eribulin for all recruited patients. (PFS 1+2). C) Time to failure of strategy.

In the 12 patients who moved to the re-administration phase, median PFS2, the primary endpoint, was 13.0 weeks (Figure 2A). Nine patients out of $12(75.0 \%)$ maintained disease control (PR; 1, SD $\geq 24$ weeks; 3, SD<24 weeks; 5, PD; 3). Seven out of nine patients $(77.8 \%)$ who achieved $\mathrm{PR}$ in the induction phase became $\mathrm{SD}$ at the eribulin readministration phase with minimal PFS2 of 11 weeks. Three out of 12 patients $(25.0 \%)$ became $\mathrm{PD}$ at the readministration phase. In the ITT population, the total PFS of ERI, which is the sum of PFS1 and PFS2, was 30.0 weeks, and TSF was 39.9 weeks (Figure 2B and C). The efficacy and administration period of every participant are shown in Figure 3.

Safety analysis. Observed adverse events during the entire protocol treatment are shown in Table II. Hematological adverse events of any grade were observed in all patients. The most common grade 3 or 4 hematologic adverse event was neutropenia (7 patients; 46.7\%), followed by leukopenia (4 patients; $26.7 \%$ ). Febrile neutropenia was seen in two patients (13.3\%). The most common non-hematological adverse event of any grade was alopecia, which occurred in all participants and the second most common event was fatigue (11 patients; $73.3 \%$ ) followed by sensory neuropathy (8 patients; $53.3 \%$ ), and fever ( 8 patients; $53.3 \%$ ). Grade 3 or higher nonhematologic adverse events were not reported. Although liver dysfunction was frequently observed in laboratory tests, almost all events were grade 1 or 2 , except for one grade 3 event of increasing lactate dehydrogenase levels.

One patient died of intracranial hemorrhage after the end of the S-1 phase.

After investigation from the data and safety monitoring committee, it was concluded that the event was incidental and unlikely to be related to protocol treatment. Otherwise, no grade 3 or more adverse events were observed during the S-1 phase. 


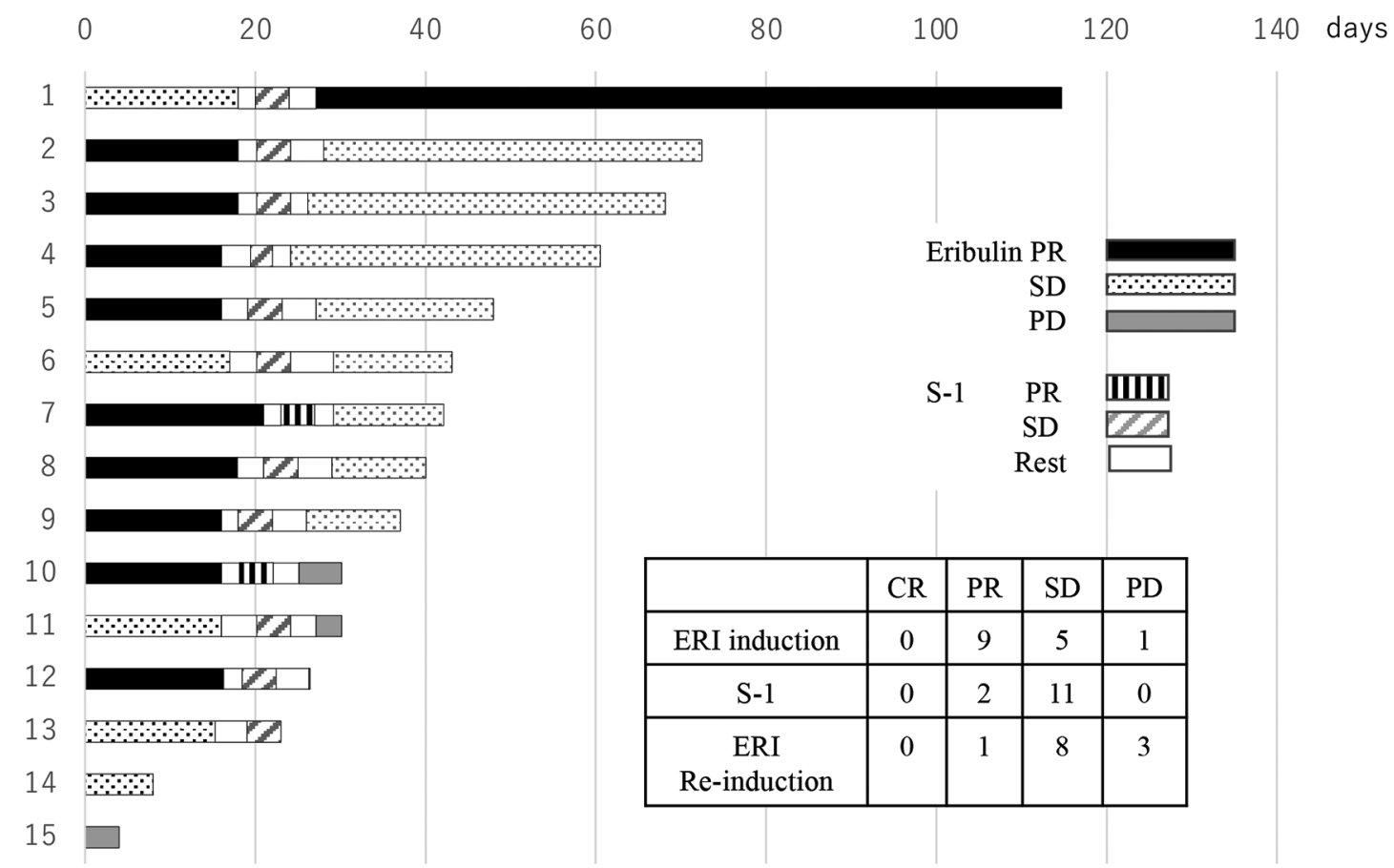

Figure 3. Swimmer plot for efficacy and duration of treatment. ERI: Eribulin; CR: complete response; PR: partial response; SD: stable disease; PD: progressive disease.

Table II. Adverse events of eribulin.

\begin{tabular}{|c|c|c|c|c|c|c|}
\hline & \multicolumn{2}{|c|}{$\begin{array}{l}\text { Induction phase } \\
\qquad \mathrm{n}=15\end{array}$} & \multicolumn{2}{|c|}{$\begin{array}{c}\mathrm{S}-1 \text { phase } \\
\mathrm{n}=13\end{array}$} & \multicolumn{2}{|c|}{$\begin{array}{l}\text { Re-administration phase } \\
\mathrm{n}=12\end{array}$} \\
\hline & Any & $\geq \mathrm{G} 3$ & Any & $\geq \mathrm{G} 3$ & Any & $\geq \mathrm{G} 3$ \\
\hline Leukocytopenia & $14(93 \%)$ & $4(27 \%)$ & $5(38 \%)$ & 0 & $8(67 \%)$ & 0 \\
\hline Neutropenia & $13(87 \%)$ & $7(47 \%)$ & $4(31 \%)$ & 0 & $8(67 \%)$ & 2 \\
\hline Anemia & $11(73 \%)$ & 0 & $4(31 \%)$ & 0 & $6(50 \%)$ & 0 \\
\hline Thrombocytopenia & $6(40 \%)$ & 0 & $4(31 \%)$ & 0 & $5(42 \%)$ & 0 \\
\hline AST & $9(60 \%)$ & 0 & $2(15 \%)$ & 0 & $2(17 \%)$ & 0 \\
\hline ALT & $9(60 \%)$ & 0 & $2(15 \%)$ & 0 & $2(17 \%)$ & 0 \\
\hline Febrile neutropenia & $2(13 \%)$ & $2(13 \%)$ & 0 & 0 & 0 & 0 \\
\hline Sensory neuropathy & $6(40 \%)$ & 0 & $5(38 \%)$ & 0 & $6(50 \%)$ & 0 \\
\hline Motor neuropathy & $3(20 \%)$ & 0 & $1(8 \%)$ & 0 & $2(17 \%)$ & 0 \\
\hline Fatigue & $11(73 \%)$ & 0 & 0 & 0 & $6(50 \%)$ & 0 \\
\hline Fever & $8(53 \%)$ & 0 & 0 & 0 & $2(17 \%)$ & 0 \\
\hline Nausea & $5(33 \%)$ & 0 & $4(31 \%)$ & 0 & $1(8 \%)$ & 0 \\
\hline Vomiting & 0 & 0 & 0 & 0 & 0 & 0 \\
\hline Anorexia & $7(47 \%)$ & 0 & $1(8 \%)$ & 0 & 0 & 0 \\
\hline Constipation & $4(27 \%)$ & 0 & 0 & 0 & $1(8 \%)$ & 0 \\
\hline Diarrhea & $2(13 \%)$ & 0 & $1(8 \%)$ & 0 & $1(8 \%)$ & 0 \\
\hline Stomatitis & $7(47 \%)$ & 0 & $1(8 \%)$ & 0 & $3(25 \%)$ & 0 \\
\hline Dysgeusia & $6(40 \%)$ & 0 & 0 & 0 & $3(25 \%)$ & 0 \\
\hline Alopecia & $15(100 \%)$ & - & 0 & 0 & $12(100 \%)$ & - \\
\hline Rash & $5(33 \%)$ & 0 & 0 & 0 & $1(8 \%)$ & 0 \\
\hline Arthralgia & 0 & 0 & 0 & 0 & $1(8 \%)$ & 0 \\
\hline Edema & 0 & 0 & 0 & 0 & $1(8 \%)$ & 0 \\
\hline Skin pigmentation & 0 & 0 & $3(23 \%)$ & 0 & 0 & 0 \\
\hline
\end{tabular}

AST: Aspartate aminotransferase; ALT: alanine transaminase. 
The observed adverse events during ERI re-induction phase are also shown in Table II. Hematological adverse events of any grade were observed in all of the patients. However, regarding grade 3 or 4 hematologic adverse events, there were only two cases of grade 4 neutropenia. With regard to non-hematological adverse events other than alopecia, sensory neuropathy (6 patients; $50 \%$, grade $1 ; 4$, grade $2 ; 2$ ) and fatigue (6 patient; $50 \%$, grade $1 ; 6)$ were common, however, no patient experienced grade 3 or more events. In laboratory tests, grade 1 or 2 mild liver dysfunction including four cases of grade 1 hyperbilirubinemia were observed.

\section{Discussion}

Eribulin has low non-hematological toxicity and can be administered while maintaining patient's quality of life. A phase II trial that we previously conducted to estimate the efficacy of eribulin as a 1st-line chemotherapy for HER2negative advanced breast cancer demonstrated an ORR of $56 \%$ and a PFS of 25 weeks (4).

In this study, nine out of 15 participants $(60 \%)$ obtained PR in the ERI induction phase, similar to our previous trial. These two trials suggested high efficacy of ERI as first-line chemotherapy for MBC. Results from two other single-arm trials of eribulin used as first and second-line chemotherapy conducted in Japan, showed a response rate of around $40 \%$ $(9,10)$. In addition to these high response rate, ERI has the effect of reducing the development of new metastatic lesions which indicate poor prognosis (11). Fujii et.al reported that the appearance rate of new metastatic lesions was significantly lower in the patients treated with ERI in the 1stline setting than those who treated in late-line setting (12).

On the other hand, S-1 is a combination drug, based on a biochemical modification of fluorouracil, containing tegafur, gimeracil, and oteracil in a molar ratio of 1:0.4:1 (13). This combination increases the fluorouracil concentration and avoids gastrointestinal toxicities. It has been used for the treatment of various solid tumors, including gastric $(14,15)$, colorectal $(16,17)$, pancreatic $(18)$, lung $(19,20)$, and breast cancer (21). Two phase II studies on S-1 in previously treated and untreated patients with MBC have been conducted in Japan, which demonstrated an ORR of $42.0 \%$ for treated patients and $40.7 \%$ for untreated patients (21).

Non-hematological side effect profiles of ERI and S-1 differ significantly. Based on safety profiles of eribulin monotherapies (1), frequently observed grade 3 or 4 nonhematological adverse events were peripheral neuropathy $(9 \%)$ and fatigue $(9 \%)$. Gastrointestinal toxicities were generally mild. In contrast, the most common grade 3 or 4 non-hematological adverse events of S-1 monotherapy were fatigue (3\%), diarrhea (3\%), and anorexia (3\%). Although all grade gastrointestinal toxicities were frequent, peripheral neuropathy was rare $(<1 \%)(22)$.
In general, cancer cells become resistant after the continued use of the same chemotherapeutic agent, and cytotoxic activity disappears. Previous studies suggested that multiple-drug resistance is associated with the overexpression of a drug efflux pump (23); especially the ATPbinding cassette $(\mathrm{ABC})$-family proteins $(24,25)$. We have also reported the result of a study that TUBB3 was considered to be a cause of ERI resistance (26), however, the mechanism of ERI resistance is still unclear.

In our previous study of ERI-based first-line chemotherapy, the median PFS was 25 weeks, suggesting that resistance occurs before 20 weeks. It was thought that a resting period of about 2 months and changing to $S-1$, which mechanism of action and side effect profile are different from ERI, before the appearance of resistance, it is possible to prevent resistance and reduce side effects, such as peripheral neuropathy.

In this study, re-introduction of eribulin led to a PFS2 of 13 weeks. The threshold for PFS2 was set at 2.5 months, and the expected value was set at 4 months. Furthermore, the duration of eribulin administration was not shortened compared to conventional continuous administration up to PD. Regarding S-1 phase, S-1 was administered for only one cycle, thus it was difficult to evaluate its efficacy, however, there was no case of marked progression.

Watanabe et al. reported efficacy of re-introduction of ERI as a part of their retrospective cohort study (27). Twentyeight of estrogen receptor-positive MBC patients who responded to the first round of ERI received re-introduction of ERI after a median of two other regimens, including endocrine therapy. They showed a median of 14 weeks (range $=62-132$ days) of TTF with $20 \%$ of $\mathrm{SD} \geq 24$ weeks, that is consistent with our results. No new adverse events due to re-introduction of ERI were observed, which seemed to be well tolerated.

Unfortunately, this study failed to reach the target number of patients, therefore no definitive findings were obtained. However, it was found that in some extent, patients could maintain response by re-administration of eribulin. Further investigation is needed to determine if S-1 is appropriate as an intervening drug and how many cycles are appropriate.

\section{Conflicts of Interest}

Tsutomu Takashima reports receiving personal fees from Eisai Co., Ltd., Taiho Pharmaceutical Co., Ltd., Eli Lilly Japan K.K., Pfizer Japan Inc., AstraZeneca K.K., and Nippon Kayaku Co., Ltd.; Shinichiro Kashiwagi reports receiving personal fees from Eisai Co., Ltd.,Chugai Pharmaceutical Co., Ltd., Pfizer Japan Inc., Eli Lilly Japan K.K., Novartis Pharma K.K., AstraZeneca K.K., Daiichi Sankyo Co., Kyowa Kirin Co., Ltd. Asahi Kasei Pharma Co., Ltd., and Becton, Dickinson and Company. Masaichi Ohira reports receiving personal fees from Taiho Pharmaceutical Co., Ltd., Chugai Pharmaceutical Co., Ltd., Ono Pharmaceutical Co., 
Ltd., Daiichi Sankyo Co., Ltd., and Otsuka Pharmaceutical Co., Ltd. Shigehiko Nishimura, Hidemi Kawajiri, Yoko Mizuyama, Shinya Tokunaga, Takeo Nishimori, Shigehito Yamagata, Kenji Tezuka, Seika Tei, Takeshi Sunami, Katsumi Ikeda, Yoshinari Ogawa, Satoru Noda, Naoyoshi Onoda, Tetsuro Ishikawa, Shinzoh Kudoh, Minoru Takada and Kosei Hirakawa declare no conflicts of interest in regard to this study.

\section{Authors' Contributions}

TT, ST, SK, SN, HK, SN, TN, KI, YO, YM, TS, KT, SY, ST, NO TI, KH and MO contributed to conception and design. TT, ST, SN, MT, HK, SK, ST, SY, SN, TN, YM, TS, KT, and TI contributed towards provision of patients. ST, TT, HK, SN, and SK contributed towards collection and assembly of data. TT, ST, SN, TI, SK, MT, $\mathrm{KI}$ and $\mathrm{YO}$ contributed towards data analysis and interpretation. All Authors contributed to drafting of the manuscript. All Authors read and approved the final manuscript.

\section{Acknowledgements}

The Authors would like to express their deepest gratitude to the women who participated in this trial and their family members, in addition to the investigators and all staff members at the study sites for their contribution to the study. This trial was conducted under the financial support of Eisai Co., Ltd.

\section{References}

1 Cortes J, O'Shaughnessy J, Loesch D, Blum JL, Vahdat LT, Petrakova K, Chollet P, Manikas A, Diéras V, Delozier T, Vladimirov V, Cardoso F, Koh H, Bougnoux P, Dutcus CE, Seegobin S, Mir D, Meneses N, Wanders J, Twelves C and EMBRACE (Eisai Metastatic Breast Cancer Study Assessing Physician's Choice Versus E7389) investigators: Eribulin monotherapy versus treatment of physician's choice in patients with metastatic breast cancer (EMBRACE): a phase 3 open-label randomised study. Lancet 377(9769): 914-923, 2011. PMID: 21376385. DOI: 10.1016/S0140-6736(11)60070-6

2 Kaufman PA, Awada A, Twelves C, Yelle L, Perez EA, Velikova G, Olivo MS, He Y, Dutcus CE and Cortes J: Phase III openlabel randomized study of eribulin mesylate versus capecitabine in patients with locally advanced or metastatic breast cancer previously treated with an anthracycline and a taxane. J Clin Oncol 33(6): 594-601, 2015. PMID: 25605862. DOI: 10.1200/JCO.2013.52.4892

3 Twelves C, Cortes J, Vahdat L, Olivo M, He Y, Kaufman PA and Awada A: Efficacy of eribulin in women with metastatic breast cancer: a pooled analysis of two phase 3 studies. Breast Cancer Res Treat 148(3): 553-561, 2014. PMID: 25381136. DOI: 10.1007/s10549-014-3144-y

4 Takashima T, Tokunaga S, Tei S, Nishimura S, Kawajiri H, Kashiwagi S, Yamagata S, Noda S, Nishimori T, Mizuyama Y, Sunami T, Tezuka K, Ikeda K, Ogawa Y, Onoda N, Ishikawa T, Kudoh S, Takada M and Hirakawa K: A phase II, multicenter, single-arm trial of eribulin as first-line chemotherapy for HER2negative locally advanced or metastatic breast cancer. Springerplus 5: 164, 2016. PMID: 27026861. DOI: 10.1186/ s40064-016-1833-1
5 Toulmonde $\mathrm{M}$, Madranges $\mathrm{N}$, Brouste V, Donamaria C, MacGrogan G, Durand M, Bonnefoi H, Mauriac L and Debled M: Docetaxel rechallenge after a first response in non-resistant metastatic breast cancer: significant activity with manageable toxicity. Breast Cancer Res Treat 134(1): 325-332, 2012. PMID: 22531859. DOI: 10.1007/s10549-012-2060-2

6 Eisenhauer EA, Therasse P, Bogaerts J, Schwartz LH, Sargent D, Ford R, Dancey J, Arbuck S, Gwyther S, Mooney M, Rubinstein L, Shankar L, Dodd L, Kaplan R, Lacombe D and Verweij J: New response evaluation criteria in solid tumours: revised RECIST guideline (version 1.1). Eur J Cancer 45(2): 228-247, 2009. PMID: 19097774. DOI: 10.1016/j.ejca. 2008.10 .026

7 Smith TJ, Khatcheressian J, Lyman GH, Ozer H, Armitage JO, Balducci L, Bennett CL, Cantor SB, Crawford J, Cross SJ, Demetri G, Desch CE, Pizzo PA, Schiffer CA, Schwartzberg L, Somerfield MR, Somlo G, Wade JC, Wade JL, Winn RJ, Wozniak AJ and Wolff AC: 2006 update of recommendations for the use of white blood cell growth factors: an evidence-based clinical practice guideline. J Clin Oncol 24(19): 3187-3205, 2006. PMID: 16682719. DOI: 10.1200/JCO.2006.06.4451

8 Cancer Therapy Evaluation Program (CTEP). Common terminology criteria for adverse events (CTCAE) v4.0. Available at: http://ctep.cancer.gov/protocol Development/electronic applications/ctc.htm\#ctc_40. [Last accessed on March 11, 2021]

9 Hayashida T, Jinno H, Mori K, Sato H, Matsui A, Sakurai T, Hattori H, Takayama S, Wada M, Takahashi M, Seki H, Seki T, Nagayama A, Matsumoto A and Kitagawa Y: Phase II trial of eribulin mesylate as a first- or second-line treatment for locally advanced or metastatic breast cancer: a multicenter, single-arm trial. BMC Cancer 18(1): 701, 2018. PMID: 29954362. DOI: 10.1186/s 12885-018-4628-7

10 Kimura K, Iwamoto M, Tanaka S, Yamamoto D, Yoshidome K, Ogura H, Terasawa R, Matsunami N, Takahashi Y, Nitta T, Morimoto T, Fujioka H, Kawaguchi K and Uchiyama K: A phase II, multicenter, single-arm trial of eribulin as first- or secondline chemotherapy for HER2-negative advanced or metastatic breast cancer: evaluation of efficacy, safety, and patient-reported outcomes. Cancer Chemother Pharmacol 81(5): 923-933, 2018. PMID: 29594360. DOI: 10.1007/s00280-018-3567-y

11 Twelves C, Cortes J, Kaufman PA, Yelle L, Awada A, Binder TA, Olivo M, Song J, O'Shaughnessy JA, Jove M and Perez EA: "New" metastases are associated with a poorer prognosis than growth of pre-existing metastases in patients with metastatic breast cancer treated with chemotherapy. Breast Cancer Res 17(1): 150, 2015. PMID: 27391598. DOI: 10.1186/s13058-0150657-1

12 Fujii T, Tokuda S, Nakazawa Y, Kurozumi S, Obayashi S, Yajima R and Shirabe K: Eribulin suppresses new metastases in patients with metastatic breast cancer. In Vivo 34(2): 917-921, 2020. PMID: 32111804. DOI: 10.21873/invivo.11858

13 Shirasaka T, Nakano K, Takechi T, Satake H, Uchida J, Fujioka A, Saito H, Okabe H, Oyama K, Takeda S, Unemi N and Fukushima M: Antitumor activity of $1 \mathrm{M}$ tegafur-0.4 M 5chloro-2,4-dihydroxypyridine-1 M potassium oxonate (S-1) against human colon carcinoma orthotopically implanted into nude rats. Cancer Res 56(11): 2602-2606, 1996. PMID: 8653704.

14 Sakuramoto S, Sasako M, Yamaguchi T, Kinoshita T, Fujii M, Nashimoto A, Furukawa H, Nakajima T, Ohashi Y, Imamura H, 
Higashino M, Yamamura Y, Kurita A, Arai K and ACTS-GC Group: Adjuvant chemotherapy for gastric cancer with S-1, an oral fluoropyrimidine. N Engl J Med 357(18): 1810-1820, 2007. PMID: 17978289. DOI: 10.1056/NEJMoa072252

15 Koizumi W, Narahara H, Hara T, Takagane A, Akiya T, Takagi M, Miyashita K, Nishizaki T, Kobayashi O, Takiyama W, Toh Y, Nagaie T, Takagi S, Yamamura Y, Yanaoka K, Orita H and Takeuchi M: S-1 plus cisplatin versus S-1 alone for first-line treatment of advanced gastric cancer (SPIRITS trial): a phase III trial. Lancet Oncol 9(3): 215-221, 2008. PMID: 18282805. DOI: 10.1016/S1470-2045(08)70035-4

16 Muro K, Boku N, Shimada Y, Tsuji A, Sameshima S, Baba H, Satoh T, Denda T, Ina K, Nishina T, Yamaguchi K, Takiuchi H, Esaki T, Tokunaga S, Kuwano H, Komatsu Y, Watanabe M, Hyodo I, Morita S and Sugihara K: Irinotecan plus S-1 (IRIS) versus fluorouracil and folinic acid plus irinotecan (FOLFIRI) as second-line chemotherapy for metastatic colorectal cancer: a randomised phase 2/3 non-inferiority study (FIRIS study). Lancet Oncol 11(9): 853-860, 2010. PMID: 20708966. DOI: 10.1016/S1470-2045(10)70181-9

17 Yamada Y, Takahari D, Matsumoto H, Baba H, Nakamura M, Yoshida K, Yoshida M, Iwamoto S, Shimada K, Komatsu Y, Sasaki Y, Satoh T, Takahashi K, Mishima H, Muro K, Watanabe M, Sakata Y, Morita S, Shimada Y and Sugihara K: Leucovorin, fluorouracil, and oxaliplatin plus bevacizumab versus S-1 and oxaliplatin plus bevacizumab in patients with metastatic colorectal cancer (SOFT): an open-label, non-inferiority, randomised phase 3 trial. Lancet Oncol 14(13): 1278-1286, 2013. PMID: 24225157. DOI: 10.1016/S1470-2045(13)70490-X

18 Ueno H, Ioka T, Ikeda M, Ohkawa S, Yanagimoto H, Boku N, Fukutomi A, Sugimori K, Baba H, Yamao K, Shimamura T, Sho M, Kitano M, Cheng AL, Mizumoto K, Chen JS, Furuse J, Funakoshi A, Hatori T, Yamaguchi T, Egawa S, Sato A, Ohashi Y, Okusaka T and Tanaka M: Randomized phase III study of gemcitabine plus S-1, S-1 alone, or gemcitabine alone in patients with locally advanced and metastatic pancreatic cancer in Japan and Taiwan: GEST study. J Clin Oncol 31(13): 1640-1648, 2013. PMID: 23547081. DOI: 10.1200/JCO.2012.43.3680

19 Okamoto I, Yoshioka H, Morita S, Ando M, Takeda K, Seto T, Yamamoto N, Saka H, Asami K, Hirashima T, Kudoh S, Satouchi M, Ikeda N, Iwamoto Y, Sawa T, Miyazaki M, Tamura K, Kurata T, Fukuoka M and Nakagawa K: Phase III trial comparing oral S-1 plus carboplatin with paclitaxel plus carboplatin in chemotherapy-naïve patients with advanced nonsmall-cell lung cancer: results of a west Japan oncology group study. J Clin Oncol 28(36): 5240-5246, 2010. PMID: 21079147. DOI: $10.1200 / \mathrm{JCO} .2010 .31 .0326$

20 Kubota K, Sakai H, Katakami N, Nishio M, Inoue A, Okamoto H, Isobe H, Kunitoh H, Takiguchi Y, Kobayashi K, Nakamura Y, Ohmatsu H, Sugawara S, Minato K, Fukuda M, Yokoyama A, Takeuchi M, Michimae H, Gemma A, Kudoh S and Tokyo Cooperative Oncology Group: A randomized phase III trial of oral S-1 plus cisplatin versus docetaxel plus cisplatin in Japanese patients with advanced non-small-cell lung cancer: TCOG0701 CATS trial. Ann Oncol 26(7): 1401-1408, 2015. PMID: 25908605. DOI: $10.1093 /$ annonc/mdv 190
21 Saek T, Takashima S, Sano M, Horikoshi N, Miura S, Shimizu S, Morimoto K, Kimura M, Aoyama H, Ota J, Noguchi S and Taguchi T: A phase II study of S-1 in patients with metastatic breast cancer-a Japanese trial by the S-1 Cooperative Study Group, Breast Cancer Working Group. Breast Cancer 11(2): 194202, 2004. PMID: 15550867. DOI: 10.1007/BF02968301

22 Takashima T, Mukai H, Hara F, Matsubara N, Saito T, Takano T, Park Y, Toyama T, Hozumi Y, Tsurutani J, Imoto S, Watanabe T, Sagara Y, Nishimura R, Shimozuma K, Ohashi Y and SELECT BC Study Group: Taxanes versus S-1 as the first-line chemotherapy for metastatic breast cancer (SELECT BC): an open-label, non-inferiority, randomised phase 3 trial. Lancet Oncol 17(1): 90-98, 2016. PMID: 26617202. DOI: 10.1016/S1470-2045(15)00411-8

23 Holohan C, Van Schaeybroeck S, Longley DB and Johnston PG: Cancer drug resistance: an evolving paradigm. Nat Rev Cancer 13(10): 714-726, 2013. PMID: 24060863. DOI: 10.1038/nrc3599

$24 \mathrm{Oba} \mathrm{T}$, Izumi $\mathrm{H}$ and Ito $\mathrm{KI}$ : $\mathrm{ABCB} 1$ and $\mathrm{ABCC} 11$ confer resistance to eribulin in breast cancer cell lines. Oncotarget 7(43): 70011-70027, 2016. PMID: 27588398. DOI: 10.18632/ oncotarget. 11727

25 Baguley BC: Multiple drug resistance mechanisms in cancer. Mol Biotechnol 46(3): 308-316, 2010. PMID: 20717753. DOI: 10.1007/s12033-010-9321-2

26 Goto W, Kashiwagi S, Asano Y, Takada K, Takahashi K, Fujita H, Takashima T, Shibutani M, Amano R, Tomita S, Hirakawa K and Ohira M: The effects of eribulin on breast cancer microenvironment identified using eribulin-resistant breast cancer cell lines. Anticancer Res 39(8): 4031-4041, 2019. PMID: 31366485. DOI: 10.21873 /anticanres.13559

27 Watanabe J, Saito M, Horimoto Y and Nakamoto S: A maintained absolute lymphocyte count predicts the overall survival benefit from eribulin therapy, including eribulin readministration, in HER2-negative advanced breast cancer patients: a single-institutional experience. Breast Cancer Res Treat 181(1): 211-220, 2020. PMID: 32249370. DOI: $10.1007 / \mathrm{s} 10549-020-05626-1$
Received July 17, 2021

Revised August 24, 2021

Accepted August 25, 2021 